\title{
Falhas de mercado e falhas de governo: uma revisão da literatura sobre regulação econômica ${ }^{1}$
}

\author{
Humberto Alves de Campos²
}

\section{Resumo}

O objetivo deste artigo é fazer uma breve revisão da literatura sobre regulação econômica sob uma perspectiva econômica, apresentando os argumentos de duas abordagens que se destacaram nos estudos sobre o tema. De um lado, a análise normativa como uma teoria positiva da regulação que estuda como deve ser feita a intervenção na economia; e de outro, a teoria econômica da regulação que procura entender como a regulação é feita, incluindo as variáveis políticas.

Palavras-chave: Regulação econômica. Teoria econômica da regulação. Falhas de mercado. Falhas de governo. Escolha pública.

\section{Introdução}

Regulação econômica é um tema estudado nos campos da Economia, do Direito e da Ciência Política. Cada uma dessas áreas aponta aspectos importantes deste assunto complexo. A Economia tem tradicionalmente considerado a regulação de certos tipos de indústrias ou grupos de indústrias, avaliando como os incentivos econômicos podem ser instrumentos de políticas públicas, no plano microeconômico. A Ciência Política tem se preocupado com os fenômenos políticos e governamentais para a formulação e implementação das políticas públicas.

\footnotetext{
${ }^{1}$ O presente artigo foi apresentado como trabalho final da disciplina Direito Econômico da Regulação, ministrada pela Professora Dra. Neide Teresinha Malard, no Programa de Mestrado em Direito e Políticas Públicas do Centro Universitário de Brasília - UniCEUB no $1^{\circ}$ semestre de 2008.

${ }^{2} \mathrm{O}$ Autor é bacharel em Direito e em Administração de Empresas, pós-graduado em Direito Público e mestrando em Direito e Políticas Públicas pelo Centro Universitário de Brasília - UniCEUB. Atualmente, é integrante da carreira de Especialista em Políticas Públicas e Gestão Governamental do Ministério do Planejamento, Orçamento e Gestão.
} 
O Direito está voltado para o conjunto de regras adotado e a efetividade de sua aplicação, bem assim para as regras dos procedimentos administrativos ${ }^{3}$.

No campo da Economia, a regulação econômica é analisada por duas óticas que se destacaram nos estudos sobre o tema. De um lado, há uma abordagem que procura definir as condições e os princípios da intervenção regulatória na atividade econômica, chamada de análise normativa como uma teoria positiva ${ }^{4}$ da regulação que define as condições e os princípios da intervenção na economia. De outro, uma abordagem positiva, que se convencionou denominar teoria econômica da regulação, que procura entender como o processo regulatório se organiza, incluindo as variáveis políticas. Esta escola, portanto, incorpora elementos da ciência política na análise da intervenção do Estado na economia.

O objetivo deste artigo é fazer uma breve abordagem do tema regulação, sob uma perspectiva econômica, apresentando os argumentos das duas abordagens acima mencionadas.

\section{Regulação}

Os estudos sobre regulação econômica foram realizados, originalmente, em países de língua inglesa. "Regulation" é o termo que se refere à atividade desenvolvida pelo Estado. "Regulator" é o sujeito que promove a "regulation". A tradução mais própria para nosso vernáculo seria "regulamentação", para a atividade, e "regulamentador", para o sujeito. Entretanto, na terminologia consagrada no Direito brasileiro, a expressão regulamentação corresponde ao detalhamento da aplicação de uma norma de cunho abstrato e geral ${ }^{5}$.

De forma mais restrita, a regulamentação corresponde ao desempenho de atividade executiva. A Constituição Federal prevê no art. 84, inc. IV, que incumbe ao Presidente da República, dentre outras competências, "sancionar, promulgar e fazer publicar as leis, bem como expedir decreto e regulamentos para sua fiel execução". O conceito "regulation", porém, é muito mais amplo e qualita-

\footnotetext{
${ }^{3}$ SPULBER, Daniel F. Regulation and markets. Massachusets: MIT, 1989. p. 22.

${ }^{4} \mathrm{O}$ termo positivo é tomado no sentido descritivo.

${ }^{5}$ JUSTEN FILHO, Marçal. O direito das agências reguladoras independentes. São Paulo: Dialética, 2002. p. 15-16.
} 
tivamente distinto, conduzindo à utilização da expressão "regulação" ao invés de "regulamentação" 6 .

A regulação pode incidir sobre qualquer objeto social, como a saúde a família, a educação, a saúde ou o trabalho. No entanto, é no âmbito da Economia que o termo vem sendo utilizado mais frequentemente no Direito brasileiro. E é no âmbito do Direito Econômico que o tema vem sendo tratado como maior profundidade .

Em uma tentativa de chegar a um conceito conclusivo sobre o termo regulação, Alexandre Santos de Aragão afirma que:

A regulação estatal da economia é o conjunto de medidas legislativas, administrativas e convencionais, abstratas ou concretas, pelas quais o Estado, de maneira restritiva da liberdade privada ou meramente indutiva, determina, controla ou influencia o comportamento dos agentes econômicos, evitando que lesem os interesses sociais definidos no marco da Constituição e orientando-os em direções socialmente desejáveis8.

A professora Maria Sylvia Zanello Di Pietro define a regulação, no âmbito jurídico, de forma ampla, abrigando a regulação social e a regulação econômica. Assim, a "regulação constitui-se como o conjunto de regras de conduta e de controle da atividade econômica pública e privada e das atividades sociais não exclusivas do Estado, com a finalidade de proteger o interesse público"9.

A regulação, em uma visão mais restritiva, visaria exclusivamente garantir o equilíbrio do mercado, coibindo práticas distorcidas dos agentes econômicos. Isto é, a regulação teria o objetivo de corrigir as falhas de mercado, assegurando o equilíbrio interno do sistema regulado. Porém, em uma visão mais alargada, a função reguladora deveria ser mais ampla, devendo atuar na

\footnotetext{
${ }^{6}$ JUSTEN FILHO, Marçal. O direito das agências reguladoras independentes. São Paulo: Dialética, 2002. p. 15-16.

${ }^{7}$ DI PIETRO, Maria Sylvia Zanello. Limites da função reguladora das agências diante do princípio da legalidade. In: DI PIETRO, Maria Sylvia Zanello (Coord.) Direito regulatório: temas polêmicos. 2. ed. Belo Horizonte: Fórum, 2004. p. 19-50.

${ }^{8}$ ARAGÃO, Alexandre Santos de. Agências reguladoras e a evolução do direito administrativo econômico. Rio de Janeiro: Forense, 2004. p. 37.

${ }^{9}$ DI PIETRO, op. cit., p. 19-50.
} 
manutenção do funcionamento do mercado, bem assim buscando introduzir objetivos de ordem geral que não seriam alcançados exclusivamente pela iniciativa privada ${ }^{10}$.

\section{A justificativa para a regulação econômica: falhas de mercado}

Nos termos de Posner, "regulação econômica é a expressão que se refere a todos os tipos de impostos subsídios, bem como os controle legislativo e administrativo explícitos sobre taxas, ingresso no mercado e outras facetas da atividade econômica" ${ }^{11}$.

Até o começo dos anos 60, a teoria dominante sobre a regulação era aquela denominada como "análise normativa como uma teoria positiva" (NPT). Essa teoria considera que as falhas de mercado são as razões que levam à regulação de determinada atividade econômica. Uma vez adotadas medidas regulatórias, supõese que os agentes reguladores diminuem ou eliminam as ineficiências geradas pelas falhas de mercado. No início dos anos 60 , a falha de mercado mais popular era o monopólio natural ${ }^{12}$, seguido, a distância, pelas externalidades ${ }^{13}$.

A análise normativa da regulação "vê a formulação e a implementação de políticas como um problema técnico, ou mesmo como um problema de controle de engenharia" ${ }^{14}$. Mesmo ao tentar incluir limitações de informação, externalida-

${ }^{10}$ MARQUES NETO, Floriano de Azevedo. Agências reguladoras independentes: fundamentos e seu regime jurídico. Belo Horizonte: Fórum, 2005. p. 35.

${ }^{11}$ POSNER, Richard A. Theories of economic regulation. [S.1.]: NBER, 1974. (Working paper, n. 41$)$.p. 1.

${ }^{12}$ Um monopólio natural é uma empresa que tem capacidade de produção para todo o mercado com um custo inferior ao que existiria se houvesse outras empresas. O monopólio natural surge onde há grandes economias de escala. Se as empresas são divididas para competir entre si, o custo médio de cada uma seria maior do que o custo do monopólio original. PINDYCK, Robert S.; RUBINFELD Daniel L. Microeconomia. 5. ed. São Paulo: Prentice Hall, 2002. p. 348.

${ }^{13}$ PELTZMAN, S. A teoria econômica da regulação depois de uma década de desregulação. In: MATTOS, Paulo et al. (Coord.). Regulação econômica e democracia: o debate norteamericano. São Paulo: Ed. 34, 2004. p. 81-127.

${ }^{14}$ DIXIT, A. K., 1996, p. 4 apud MUELLER, Bernardo. Regulação, informação e política: uma resenha da teoria política positiva da regulação. Revista Brasileira de Economia das Empresas, v. 1, n. 1, p. 7. 
des, risco, etc. a abordagem normativa é uma simplificação que abstrai as instituições políticas e econômicas. Os adeptos dessa abordagem argumentam que suas análises sugerem políticas que levariam a bons resultados se implementadas de acordo com usas recomendações e sem alterações pelo processo político ${ }^{15}$.

Dessa forma, a abordagem normativa procura fundamentar quando a regulação deve surgir e que forma ela deveria tomar para maximizar o bem-estar social. Essa análise, portanto, proveria uma explicação técnica para instrumentalizar uma regulação voltada para o interesse público.

A abordagem normativa está alinhada com uma linha de pensamento que está baseada na teoria do interesse público, segundo a qual a regulação é instituída com o propósito de defender o interesse público contra perdas de bem-estar associadas às falhas de mercado. Essa teoria pressupõe que os legisladores e reguladores são maximizadores do bem-estar social, buscando corrigir problemas de falhas de mercado ${ }^{16}$. Nesse sentido, a regulação econômica refere-se àquelas intervenções cujo propósito é melhorar o funcionamento do mercado, isto é, onde existam falhas de mercado ${ }^{17}$.

A lógica econômica tradicional para a regulação de falhas de mercado diz respeito aos problemas e à maximização da eficiência em mercados caracterizados por monopólios ou oligopólios ${ }^{18}$. Monopólios são comumente associados com ine-

${ }^{15}$ DIXIT, A. K., 1996, p. 4 apud MUELLER, Bernardo. Regulação, informação e política: uma resenha da teoria política positiva da regulação. Revista Brasileira de Economia de Empresas. Brasília: 2001. p. 7.

${ }^{16}$ DIXIT, A. K., 1996, p. 4 apud MUELLER, Bernardo. Regulação, informação e política: uma resenha da teoria política positiva da regulação. Revista Brasileira de Economia das Empresas, v. 1, n. 1, p. 11.

${ }^{17} \mathrm{Um}$ dos trabalhos mais influentes para a justificativa da intervenção governamental foi Welfare Economic and the Theory of the State, de William Baumol em 1952 - um estudo que simplesmente identificou falhas de mercado que deveriam ser corrigidas. Outros dois artigos estabeleceram, juntamente com o livro de Baumol, as bases do argumento da falha de mercado: The Theory of Public Expenditure, de Paul Samuelson em 1954, e The Anatomy of Market Failure, de M. Bator em 1958. Conforme MITCHELL, William C.; SIMMONS, Randy T. Para além da política: mercados, bem-estar social e o fracasso da burocracia. Rio de Janeiro: Topbooks, 2003. p. 24.

${ }^{18} \mathrm{O}$ monopólio é caracterizado quando há um único produtor de um determinado produto. $\mathrm{O}$ oligopólio existe quando apenas algumas empresas são responsáveis pela maior parte ou por toda a produção de um determinado produto. As barreiras à entrada como, por exemplo, economias de escala, acesso a patentes e tecnologia, obtenção de reputação, são as principais razões para a manutenção do monopólio ou do oligopólio conforme PINDYCK, Robert S.; RUBINFELD Daniel L. Microeconomia. 5. ed. São Paulo: Prentice Hall, 2002. p. 348-427. 
ficiências, estáticas e dinâmicas. Do ponto de vista estático, os monopólios criam ineficiências, cobrando preços muito acima dos seus custos marginais que se traduzem em lucros extraordinários. Em termos dinâmicos, os monopolistas não têm incentivos para investir em inovação tecnológica e melhora de seus produtos ou serviços o que restringe os ganhos de produtividade da economia.

A questão da externalidade também sempre foi relevante na regulação econômica. A externalidade surge quando as empresas ou indivíduos realizam ações que levam em consideração somente os benefícios e os custos privados, e não os custos e benefícios sociais. O benefício privado corresponde somente ao benefício do indivíduo que consome o bem ou serviço. $\mathrm{O}$ benefício social leva em consideração o impacto desse consumo para todos os indivíduos da sociedade ${ }^{19}$.

Quando o benefício social é maior do que o benefício privado, a externalidade é definida como positiva. Um exemplo é de um indivíduo que cuida do jardim da sua casa, beneficiando não somente ele mesmo, mas outros moradores da vizinhança. A externalidade negativa, contrariamente, é caracterizada quando os custos dos produtores ou vendedores, chamados de custos privados, não são totalmente internalizados ${ }^{20}$. Esses custos, então, são distribuídos e absorvidos pela sociedade. A degradação ambiental é um tipo de externalidade negativa na medida em que o subproduto gerado pela atividade econômica, ao ser consumido pela sociedade de forma forçada, provoca a deterioração dos fatores de produção dos demais agentes econômicos e a perda de bem-estar dos indivíduos ${ }^{21}$.

Com a expansão da atuação do Estado na economia, surgiram outras justificativas para a regulação econômica. Além das tradicionais falhas relacionadas aos monopólios e às externalidades, questões como assimetrias de informação e insuficiente provisão de bens públicos foram acrescentados como justificativas para a atuação regulatória do Estado.

\footnotetext{
${ }^{19}$ ANDRADE, Eduardo de Carvalho. Externalidades. In: ARVATE, Paulo Roberto; BIDERMAN, Ciro (Org). Economia do setor público. Rio de Janeiro: Elsevier, 2004. p. 16-33.

${ }^{20}$ Ibidem, p. 16-33.

${ }^{21}$ FERREIRA, Sandro de Freitas; ORTIZ, Ramon Arigoni. O papel do governo na preservação do meio ambiente. In: ARVATE, Paulo Roberto; BIDERMAN, Ciro (Org.). Economia do setor público. Rio de Janeiro: Elsevier, 2004. p. 34- 46.
} 
Em relação à assimetria de informação, é importante apontar que os modelos de competição de mercado se apoiam no pressuposto da informação perfeita em que os consumidores, ao tomarem sua decisão, sabem tudo o que precisam saber sobre a qualidade de um produto, preço da concorrência etc. Tal pressuposto não é realista porque obter informações tem custos, os produtos podem ser complexos ou seus efeitos somente serem sentidos no longo prazo ou, ainda, há efeitos colaterais desconhecidos ${ }^{22}$.

A assimetria de informação também permite o surgimento do risco moral e da seleção adversa. O risco moral ocorre quando as ações das partes do contrato não são diretamente observáveis e não podem ser objeto de negociação e não podem ser incorporadas ao contrato ${ }^{23}$, portanto, é um problema de ação oculta. A seleção adversa se refere à situação na qual um lado do mercado não pode observar a qualidade ou tipo dos bens no outro lado do mercado. Aqui o problema é o tipo oculto ${ }^{24}$. Um exemplo de um mercado com tais características é o mercado de seguros de saúde, no qual o segurador não sabe qual a conduta do segurado ou suas condições de saúde.

A insuficiente provisão de bens públicos também é uma falha de mercado que recorrentemente é utilizada como justificativa para a intervenção do Estado na economia. Na formulação de Paul Samuelson, os bens públicos têm a característica da não-rivalidade que faz com que o consumo de um bem público por um indivíduo não reduza o consumo por outra pessoa, isto é, o custo de fornecer o bem público para um consumidor adicional é zero, pois todos podem se beneficiar do bem sem reduzir o seu valor para os outros ${ }^{25}$. Outra característica dos bens públicos é a não-exclusividade, que significa que esse bem não pode ser mantido fora do alcance de qualquer membro de um grupo uma vez que tenha sido fornecido para o grupo, isto é, se o bem

${ }^{22}$ MITCHELL, William C.; SIMMONS, Randy T. Para além da política: mercados, bemestar social e o fracasso da burocracia. Rio de Janeiro: Topbooks, 2003. p. 53.

${ }^{23} \mathrm{O}$ fenômeno do risco moral foi identificado por ARROW, K. J. Uncertainty and welfare economics of medical care. American Economic Review, n. 53, p. 941-973, Dec. 1963. ARROW, K. J. Aspects of the theory of risk bearing. Helsinki: Yrjo Johnassonin Säatio, 1965. Cf. SPULBER, Daniel F. Regulation and markets. Massachusetts: MIT, 1989. p. 61.

${ }^{24}$ VARIAN, H. R. Microeconomia: princípios básicos. Rio de Janeiro: Campus, 1994. p. 655.

${ }^{25}$ SAMUELSON, Paul A. The pure theory of public expenditure. The Review of Economics and Statistics, v. 36, n. 4, p. 387, Nov. 1954. 
está disponível para uma pessoa, estará automaticamente disponível para os demais $^{26}$. Os exemplos mais comuns de bens públicos são a defesa nacional, a iluminação pública e a proteção policial.

Iniquidade na distribuição de renda é um poderoso argumento para a intervenção ${ }^{27}$ na atividade econômica. Os mercados recompensam as pessoas de acordo com sua contribuição à produção de bens e serviços que os consumidores gostariam de adquirir. Há dois argumentos contra a recompensa meramente baseada no mercado: falhas de mercado e injustiça. As falhas de mercado envolvem, por exemplo, a competição imperfeita e a assimetria de informação. A injustiça está ligada ao sentimento de que as capacidades genéticas das pessoas não foram conquistadas. Dessa forma, a sociedade deveria restringir os prêmios que concedem padrões de vida muito mais altos para pessoas com maior capacidade inata ${ }^{28}$.

A intervenção do Estado na economia também é lembrada como instrumento para assegurar a estabilidade da economia como um todo. A economia passa por flutuações conhecidas como ciclos econômicos. Os governos não intervinham na economia para combater ciclos econômicos até que John Maynard Keynes publicou seu General Theory of Employment, Interest, and Money, em $1936^{29}$.

O livro foi publicado sobre o forte impacto da Grande Depressão, sendo que seu argumento central era de que os mercados tinham falhas que só poderiam ser corrigidas pela atuação governamental. A proposta era de que o governo deveria produzir políticas anticíclicas, por meio de instrumentos fiscais, para manutenção do pleno emprego. Assim, quando a economia começava a declinar, o governo deveria reduzir impostos e aumentar seus

\footnotetext{
${ }^{26}$ MITCHELL, William C.; SIMMONS, Randy T. Para além da política: mercados, bemestar social e o fracasso da burocracia. Rio de Janeiro: Topbooks, 2003. p. 46.

${ }^{27} \mathrm{O}$ termo intervenção foi utilizado para diferenciar estas atuações do Estado da regulação propriamente dita que está ligada à correção de falhas de mercado - poder de mercado (monopólios ou oligopólios), informações incompletas, externalidades, provisão de bens públicos Cf. PINDYCK, Robert S.; RUBINFELD Daniel L. Microeconomia. 5. ed. São Paulo: Prentice Hall, 2002. p. 596-599.

${ }^{28}$ MITCHELL; SIMMONS, op. cit., p. 58.

${ }^{29}$ Ibidem, p. 54.
} 
gastos. Quando a economia começasse a apresentar crescimento, o governo deveria agir de forma contrária, aumentando impostos e reduzindo os gastos.

As regulações para minimizar as iniquidades de distribuição de renda e para assegurar a estabilidade da economia não são usualmente classificadas como atividades de regulação econômica. Isso porque, a primeira faz parte de uma atividade mais ampla de atuação governamental, vinculada a políticas sociais, ainda que algumas práticas regulatórias incluam subsídios cruzados com a justificativa de atenuar desigualdades sociais. A segunda é matéria de política macroeconômica, enquanto regulação econômica está ligada a microeconomia; portanto, em regra, fora do escopo de análise da regulação econômica.

É válido destacar que a perspectiva normativa incorporou um elemento importante na sua análise. A questão da assimetria de informação entre o regulador e o regulado. A assimetria de informação - que é uma falha de mercado - surge do fato que o regulador não tem todas as informações a respeito dos custos do regulado ou nível de esforço empreendido por ele. Dessa forma, a regulação eficiente que deveria buscar a eficiência regulatória máxima - o first best -, maximizando o equilíbrio entre consumidores e produtores, somente conseguiria atingir a solução second best, tendo em vista as restrições decorrentes da assimetria de informação entre regulador e regulado ${ }^{30}$.

Portanto, na linha da análise normativa, a regulação econômica vem para, na presença das "falhas de mercado", assegurar que o resultado da interação entre produtores e consumidores de determinado bem ou serviço seja eficiente, tendo como resultado adequado níveis de quantidade, qualidade e preço $^{31}$.

${ }^{30}$ MUELLER, Bernardo. Regulação, informação e política: uma resenha da teoria política positiva da regulação. Revista Brasileira de Economia de Empresas, Brasília, v. 1, n. 1, 2001. p. 6.

${ }^{31}$ Do ponto de vista da Economia, há uma tendência de concentração da regulação destes aspectos da indústria - quantidade, qualidade e preço. Vide: FIANI, Ronaldo; PINTO JR., Helder Queiroz. Regulação econômica. In: KUPFER, David; HASENCLEVER, Lia. Economia industrial: fundamentos teóricos e práticos no Brasil. Rio de Janeiro: Campus, 2002. p. 515-545. 


\section{Falhas de governo na regulação da economia: teoria econômica da regulação}

As limitações da aplicabilidade das soluções normativas, tendo em vista obstáculos de natureza política, são reconhecidas pelos próprios teóricos desta escola. Laffont e Tirole afirmam que a abordagem "não vê alguns importantes aspectos do processo de tomada de decisões dos governos e, provavelmente, os aspectos mais interessantes da ciência política" ${ }^{32}$.

No começo dos anos 70, iniciou-se uma inflexão crítica em relação à regulação econômica realizada pelo Estado. A teoria começou a identificar as falhas de governo. Em 1971, George J. Stigler, da Universidade de Chicago, publicou um artigo com a tese central de que a "regulação é adquirida pela indústria e é desenhada e operada primariamente para o seu benefício" ${ }^{33}$. Nesse artigo, é deixada de lado a visão do Estado como um ente benevolente. O Estado é retratado como uma fonte potencial de ameaça ou de recursos para toda atividade econômica na sociedade ${ }^{34}$. Estava, então, iniciado o processo à linha de estudos que se convencionaria chamar Teoria Econômica da Regulação.

O texto estendia a intuição básica da Teoria da Captura ${ }^{35}$. Essa teoria afirmava que a regulação seria originária da própria demanda por parte da indústria ou, com o passar do tempo, a regulação acabava por ser utilizada de acordo com os interesses da indústria que pretendia regular. Essa teoria é radical, no sentido em que somente os interesses dos produtores acabariam por prevalecer ${ }^{36}$.

A Teoria da Captura foi duramente criticada. Segundo Posner, não se apresenta qualquer motivo para caracterizar a interação entre agência e empresas por meio da metáfora da captura. Isso porque a teoria não apresenta qualquer razão

\footnotetext{
${ }^{32}$ LAFFONT, J. J.; J. Tirole. 1990, p. 3-6 apud MUELLER, Bernardo. Regulação, informação e política: uma resenha da teoria política positiva da regulação. Revista Brasileira de Economia de Empresas, Brasília, v. 1, n. 1, p. 8.

${ }^{33}$ STIGLER, George J. The theory of economic regulation. The Bell Journal of Economics and Management Science, v. 2, n. 1, p. 3, Spring 1971.

${ }^{34}$ Ibidem, p. 3.

${ }^{35}$ MUELLER, Bernardo. Regulação, informação e política: uma resenha da teoria política positiva da regulação. Revista Brasileira de Economia de Empresas, Brasília, v. 1, n. 1, p. 12.

${ }^{36}$ BARRIONUEVO FILHO, Arthur; LUCINDA, Cláudio Ribeiro. Teoria da regulação. In: ARVATE, Paulo Roberto; BIDERMAN, Ciro (Org.). Economia do setor público. Rio de Janeiro: Elsevier, 2004. p. 71.
} 
que explique por que o mercado regulado deveria ser o único grupo de interesse capaz de influenciar as agências. Grupos de consumidores, por exemplo, teriam forte interesse em "capturar" a agência. Da mesma forma, não se sugere por que as empresas são capazes de capturar apenas as agências que estejam estabelecidas e nunca advogar pela criação de uma agência que irá promover seus interesses, ou por que o mercado que seja suficientemente forte para capturar a agência estabelecida e domesticá-la não poderia, antes disso, impedir a criação da agência ${ }^{37}$.

A existência do fenômeno do subsídio cruzado, isto é, a prestação compulsória de serviços para determinados consumidores a preços mais baixos e, muitas vezes, abaixo do preço de custo também demonstrou a fragilidade da generalização empírica da teoria da captura ${ }^{38}$. A Teoria da Captura, portanto, tinha um problema conceitual comum à NPT; ambas eram generalizações empíricas sem uma fundamentação teórica e nenhuma delas tinha resposta para a questão "por que a regulação deve encorajar ou desconstituir monopólios"? A versão proposta por Stigler procurou responder essa questão ${ }^{39}$.

Segundo Stigler, há duas visões alternativas largamente empregadas para a regulação da indústria. A primeira é que a regulação é instituída fundamentalmente para a proteção e benefício ou do público como um todo ou para algumas parcelas do público em desvantagem na sociedade. Sob esse ponto de vista, os custos da regulação são compensados por algum objetivo social. A segunda visão é essencialmente de que o processo político carece de uma explicação racional: a política é o imponderável, mistura de forças de diversas naturezas, às vezes, compreendendo ações de grande virtude moral e, na maioria das vezes, de ações da mais baixa venalidade ${ }^{40}$.

De acordo com Posner, à primeira vista, a teoria inicialmente proposta por Stigler parece uma versão mais refinada da Teoria da Captura. Entretanto,

${ }^{37}$ POSNER, Richard A. Theories of economic regulation. NBER, 1974. p. 12-13. (Working paper, n. 41).

${ }^{38}$ PELTZMAN, S. A teoria econômica da regulação depois de uma década de desregulação. In: MATTOS, Paulo et al. (Coord.). Regulação econômica e democracia: o debate norteamericano. São Paulo: Ed. 34, 2004. p. 88.

${ }^{39}$ Ibidem, p. 81-127.

${ }^{40}$ STIGLER, George J. The theory of economic regulation. The Bell Journal of Economics and Management Science, v. 2, n. 1, p. 3, Spring 1971 
a Teoria da Regulação Econômica rejeita o inexplicado e, frequentemente, falso pressuposto do propósito virtuoso e probo da legislação; admite a possibilidade de "captura" por outros grupos de interesse, além das empresas reguladas; e substitui a metáfora "captura" por uma terminologia mais neutra de oferta e procura $^{41}$.

O Estado conta com um recurso básico que, em princípio, não é compartilhado nem mesmo com o mais poderoso dos seus cidadãos: o poder de coagir. Esse poder cria possibilidades de uma indústria utilizar o Estado para aumentar sua lucratividade. São quatro as principais práticas que uma indústria pode obter do Estado: i) subvenção direta em dinheiro; ii) controle sobre a entrada de novos concorrentes, reduzindo a concorrência; iii) políticas que afetem produtos substitutos e complementares, reduzindo possibilidade do surgimento de produtos substitutos ou incentivando indústrias complementares como, por exemplo, subsídios para aeroportos que se refletem em ganhos para as companhias aéreas; e iv) fixação de preços para alcançar taxas de retorno mais competitivas ${ }^{42}$, formando uma espécie de cartel oficializado pela regulação governamental.

A Teoria da Regulação Econômica passou a incluir a dimensão política na análise da formulação das políticas regulatórias porque, por sua natureza, a regulação necessariamente implica em uma redistribuição de renda, pois gera custos para alguns grupos e benefícios para outros. Nesse sentido, a regulação pode ser vista como um bem econômico para o qual existe um mercado com oferta e demanda em que grupos ofertam regulação e outros grupos disputam regulação favorável a seu bem-estar.

No modelo, a oferta de regulação seria feita pelos legisladores, que por sua vez são modelados como maximizadores de apoio político para a próxima eleição ${ }^{43}$, isto é, "políticos, como o resto de nós, são vistos como maximizado-

\footnotetext{
${ }^{41}$ POSNER, Richard A. Theories of economic regulation. [S.1.]: NBER, 1974. p. 14. (Working paper, n. 41).

${ }^{42}$ STIGLER, George J. Teoria da regulação econômica. In: MATTOS, Paulo et al. (Coord.). Regulação econômica e democracia: o debate norte-americano. São Paulo: Ed. 34, 2004. p. 23-48.

${ }^{43}$ MUELLER, Bernardo. Regulação, informação e política: uma resenha da teoria política positiva da regulação. Revista Brasileira de Economia de Empresas, Brasília, v. 1, n. 1, p. 12-13.
} 
res do interesse próprio" ${ }^{44}$. Dessa forma, Stigler formula uma função-objetivo do agente regulador em que sua utilidade deriva de seu orçamento e dos votos dos eleitores, superando a deficiência da Teoria da Captura que não demonstrava as motivações do regulador. No outro lado da atividade regulatória, existe a demanda por regulação, que pode ser das indústrias reguladas ou de outros grupos de interesses.

A tese, portanto, é que a ação regulatória é resultado da interação de interesses privados, orientados exclusivamente pela busca de benefícios. As indústrias reguladas querem se proteger da concorrência e outros atores buscam benefícios, criando uma demanda regulatória. Os reguladores, em contrapartida, criam uma oferta de regulação em troca de apoio político. Tratar-se-ia, então, de um verdadeiro comércio regulatório, totalmente estranho a qualquer ideia de interesse público ${ }^{45}$.

O mais interessante, no entanto, é que, utilizando a teoria desenvolvida por Mancur Olson em A Lógica da Ação Coletiva (1965), Stigler teorizou que os grupos que tivessem menores custos de organização e maiores ganhos potenciais per capita - que reduz o custo de obtenção e disseminação de informação -, seriam os grupos que teriam probabilidade de ter sucesso em influenciar o processo regulatório, e, por consequência, os maiores demandantes por regulação.

Desenvolvendo a proposta original de Stigler, Posner afirma que a Teoria Econômica da Regulação está baseada em dois pontos: o poder coercitivo do governo para fazer regulação é um produto que pode ser alocado pela lei da oferta e da procura: a Teoria dos Cartéis ${ }^{46}$ pode ser usada para identificar as curvas de oferta e procura. A

${ }^{44}$ PELTZMAN, S. The economic theory of regulation after a decade of deregulation. In: WINSTON, Clifford; BAILY Martin Neil (Ed.). Brookings papers on economic activity: microeconomics. Washington: Brookings Institution Press, 1989. p. 1.

${ }^{45}$ MATTOS, Paulo et al. (Coord.). Regulação econômica e democracia: o debate norte-americano. São Paulo: Ed. 34, 2004. p. 15.

${ }^{46}$ Segundo Ponser, "a Teoria dos Cartéis ensina que a resistência em cooperar na manutenção do preço monopolístico tem maiores chances de ser superada se o número de vendedores cujas ações devam estar coordenadas é pequeno, o que tende a reduzir os custos de coordenação e de monitoramente, e se os interesses dos vendedores são idênticos ou muito parecidos, o que reduziria o custo de firmar um acordo". Cf. POSNER, Richard A. Theories of economic regulation. [S.1.]: NBER, 1974. (Working paper, n. 41). 
concepção da regulação como produto chama a atenção para o fato que a regulação será fornecida para os indivíduos ou grupos específicos que derem mais valor para ela. Essa concepção também chama atenção para fatores relacionados aos custos de obter regulação. A Teoria dos Cartéis ajuda a clarear o aspecto dos benefícios e dos custos ${ }^{47}$.

A análise desenvolvida por Posner sugere que, apesar das características que predispõem o mercado a uma cartelização privada bem-sucedida poderem também ajudá-lo a obter regulação governamental favorável, uma característica que desencoraja a cartelização privada - um grande número de agentes cuja cooperação é necessária para criar e manter um cartel - encoraja a regulação. Um grande número de agentes tem grande poder eleitoral (indústrias e seus empregados) e uma alta assimetria de interesses que encorajam a participação em uma coalizão em busca de regulação $0^{48}$, o que não é favorável para a formação de cartéis privados, tendo em vista que um grande número de participantes aumenta os custos de formação e manutenção dos cartéis.

A Teoria da Regulação Econômica, então, poderia ser usada para explicar a grande frequência de legislação protecionista para áreas de agricultura, trabalhista, de regulamentação de profissões, em que a cartelização privada dificilmente se viabilizaria. Entretanto, Posner aponta que a teoria ainda não estava refinada a ponto de predizer em quais indústrias a regulação seria criada por demanda dos produtores $^{49}$.

Modelos subsequentes estabelecem parâmetros de análise mais sofisticados. Peltzman aperfeiçoou a Teria Econômica da Regulação com a noção de que nenhum interesse econômico captura de forma exclusiva o corpo regulatório ${ }^{50}$. Dessa forma, Peltzman

\footnotetext{
${ }^{47}$ Segundo Ponser, “a Teoria dos Cartéis ensina que a resistência em cooperar na manutenção do preço monopolístico tem maiores chances de ser superada se o número de vendedores cujas ações devam estar coordenadas é pequeno, o que tende a reduzir os custos de coordenação e de monitoramente, e se os interesses dos vendedores são idênticos ou muito parecidos, o que reduziria o custo de firmar um acordo". Cf. POSNER, Richard A. Theories of economic regulation. [S.1.]: NBER, 1974. (Working paper, n. 41). p.15-16.

${ }^{48}$ Ibidem, p. 15-16.

${ }^{49}$ Ibidem, p. 22

${ }^{50}$ SALGADO, Lucia Helena. Agências regulatórias na experiência brasileira: um panorama do atual desenho institucional. Brasília: IPEA. 2003. p. 5. (Texto para discussão, n. 941). O texto original de Peltzman é PELTZMAN, S. Towards a more general theory of regulation. Journal of Law and Economics, v. 19, n. 2, p. 211- 240, Aug. 1976.
} 
desenvolve um modelo em que os legisladores tomam decisões de regulação para maximizar a votação majoritária. O modelo atribui uma função para os políticos na formação dos grupos de interesse e por estabelecer uma função-objetivo do regulador em função de apoio político. A hipótese é que o agente regulador procura conquistar o máximo de apoio possível de ambos os grupos: dos consumidores, mantendo a tarifa tão baixa quanto puder, e da indústria, garantindo o maior lucro possível ${ }^{51}$.

Outra importante contribuição é de Becker ${ }^{52}$, com uma visão de que a riqueza da indústria (recursos dos produtores e dos consumidores) é a principal moeda política a ser distribuída da maneira que mais beneficie o regulador. Essa visão fornece uma ligação entre a teoria da regulação econômica, com sua ênfase na distribuição, e na abordagem normativa, com sua ênfase na eficiência ${ }^{53}$. O argumento central é de que a perda de bemestar social ocasionada pelas medidas de regulação é uma limitação às políticas regulatórias ineficientes. A razão é simples: conforme o regulador afasta os índices de produção do nível de eficiência, a perda de bem-estar social aumenta numa taxa crescente. A perda de bem-estar é o ganho do ganhador menos a perda do perdedor em decorrência da intervenção. Essas perdas e ganhos estimulam os grupos de interesses. Dessa forma, perdas marginais de bem-estar crescentes devem progressivamente enfraquecer os ganhadores em relação aos perdedores ${ }^{54}$. Segue-se daí, que este "peso morto" acaba por servir como limitação do aumento indefinido das atividades regulatórias ${ }^{55}$.

Por fim, é importante mencionar que a análise positiva avança no sentido de que uma política para a regulação deve ser definida por meio do conceito da "remediabilidade" (remediableness), qual seja: "uma política para a qual não existe nenhuma alternativa superior viável que possa ser implementada com ganhos líquidos é presumida como sendo eficiente ${ }^{\$ 5}$. O conceito não é convergente com a as prescrições da análise normativa,

${ }^{51}$ SPULBER, Daniel F. Regulation and markets. Massachuessetts MIT, 1989. p. 95-96.

${ }^{52}$ BECKER, Gary S. A theory of competition among pressure groups for political influence. Quarterly Journal of Economics, n. 98, p. 371-400, 1983.

${ }^{53}$ PELTZMAN, S. A teoria econômica da regulação depois de uma década de desregulação. In: MATTOS, Paulo et al. (Coord.). Regulação econômica e democracia: o debate norteamericano. São Paulo: Ed. 34, 2004. p. 81-127.

${ }^{54}$ Ibidem, p. 81-127.

${ }^{55}$ FIANI, Ronaldo. Teoria da regulação econômica: estado atual e perspectivas futuras. Rio de Janeiro. UFRJ; IE, 1998. p. 23. (Texto para discussão). Disponível em: <http://www.ie.ufrj. br/grc/pdfs/teoria_da_regulacao_economica.pdf>. Acesso em: 30 jul. 2008.

${ }^{56}$ WILLIAMSON, O. E. The Politics and Economics of Redistribution and Efficiency. In: THE MECHANISMS of governance. Oxford: Oxford University Press, 1996. p. 195. 
pois mesmo quando uma forma é superior à outra, sua implementação pode não ser politicamente possível $^{57}$.

\section{Falhas de governo: teoria da escolha pública}

Outra linha de argumento desenvolvida acerca do fenômeno regulatório nos anos 1970 foi a Teoria da Escolha Pública - TEP ${ }^{58}$. O argumento básico é que, seja no mercado, seja na política, os indivíduos comportam-se da mesma maneira, movidos pelas mesmas motivações, o interesse próprio. Assim, as políticas públicas não seriam conduzidas por motivações alheias ao interesse pessoal daqueles envolvidos-políticos, burocratas, lobistas, - em nome de alguma entidade abstrata da dimensão do interesse público ${ }^{59}$.

A TEP procura estudar os processos de decisão política numa democracia, utilizando o instrumental analítico da economia, fundamentalmente os conceitos de comportamento racional e autointeresse da ação humana. A TEP, portanto, constitui uma abordagem interdisciplinar da relação entre economia e política. A TEP se ocupa das decisões feitas por indivíduos, integrantes de um grupo ou organismo coletivo, que afetam a todos os integrantes da coletividade. Um dos principais objetivos dos trabalhos tem sido determinar como se efetivam os processos políticos e seus efeitos na economia, evidenciando a estreita relação dos resultados econômicos com as regras e procedimentos para a tomada de decisões no âmbito político ${ }^{60}$.

${ }^{57}$ SALGADO, Lucia Helena. Agências regulatórias na experiência brasileira: um panorama do atual desenho institucional. Brasília: IPEA. 2003. p. 13. (Texto para discussão, n. 941).

${ }^{58}$ É quase um consenso considerar como trabalho fundador da TEP The Calculus of Consent, dos economistas James Buchanan e Gordon Tulllok, sendo que o cientista político Anthony Downs (An Econnomic Theory of Democrazy, 1957) e os economistas Mancur Olson (The Logic of Collective Action, 1965) e William Riker (The Theory of Political Coalition, 1962) são considerados co-fundadores dessa perspectiva de análise. O trabalho de Joseph Schumpter, Capitalism, Socialism and Democracy, pode ser visto como um precursor da análise política da TEP. Conforme BORSANI. Relações entre política e economia: teoria da escolha pública In: ARVATE, Paulo Roberto; BIDERMAN, Ciro (Org.). Economia do setor público. Rio de Janeiro: Elsevier, 2004. p. 103-126.

${ }^{59}$ SALGADO, op. cit., p. 8.

${ }^{60}$ BORSANI. Relações entre política e economia: teoria da escolha pública In: ARVATE, Paulo Roberto; BIDERMAN, Ciro (Org.). Economia do setor público. Rio de Janeiro: Elsevier, 2004. p. 103-126. 
Em 1971, Niskanen lançou um trabalho ${ }^{61}$ que unificou o corpo teórico da TEP. Os burocratas foram apresentados como maximizadores de orçamento. O primeiro pressuposto é que os burocratas são indivíduos racionais que buscam a obtenção de maiores salários, oportunidades de promoção, além de prestígio e poder. Esses fatores dependem do tamanho do orçamento do bureau. O segundo é de que os burocratas conhecem as preferências dos políticos por serviços burocráticos, mas os políticos não têm meios para obter a informação precisa sobre o custo real do serviço burocrático. Com o monopólio da informação técnica, os burocratas detêm poder para obter um orçamento maior do que o necessário. O autor apresenta um modelo de monopólio bilateral, com burocratas e governo, sendo que o governo é um comprador de políticas regulatórias da burocracia ${ }^{62}$. A tese de Niskanen não é facilmente compatível com a teoria da regulação, que não trata os burocratas como protagonistas nas atividades governamentais ${ }^{63}$.

O modelo de política e democracia da escolha pública é bastante simples. Presume-se que a política seja um sistema que consiste em quatro grupos de tomadores de decisões - eleitores, políticos, burocratas e grupos de interesses. Presume-se que indivíduos sejam maximizadores racionais de utilidade que buscam benefícios do sistema político: os políticos buscam votos; os burocratas buscam segurança no trabalho e orçamentos; grupos de interesses e eleitores buscam mais riqueza e renda ${ }^{64}$.

A Teoria da Public Choice procura fornecer modelos positivos ${ }^{65}$ realistas da política e tenta achar métodos de fazer escolhas coletivas que tenham características normativas desejáveis. Ela avalia, então, os problemas da relação entre representantes e representados e preocupações com comportamento estratégico, centrais para governos representativos democráticos e para o funcio-

${ }^{61}$ NISKANEN, W. Bureaucracy and representative government. Chicago; New York: Aldine Atherton, 1971.

${ }^{62}$ BORSANI. Relações entre política e economia: teoria da escolha pública In: ARVATE, Paulo Roberto; BIDERMAN, Ciro (Org.). Economia do setor público. Rio de Janeiro: Elsevier, 2004. p. 103-126.

${ }^{63}$ SALGADO, Lucia Helena. Agências regulatórias na experiência brasileira: um panorama do atual desenho institucional. Brasília: IPEA. 2003. p. 9. (Texto para discussão, n. 941).

${ }^{64}$ MITCHELL, William C.; SIMMONS, Randy T. Para além da política: mercados, bemestar social e o fracasso da burocracia. Rio de Janeiro:Topbooks, 2003. p. 102.

${ }^{65} \mathrm{O}$ termo positivo é usado como sinônimo de descritivo, em oposição a normativo. 
namento das burocracias. A análise normativa especifica condições desejáveis para procedimentos de escolha coletiva e procura processos decisórios que satisfaçam essas condições ${ }^{66}$.

As instituições e regras políticas são centrais para a TEP. As instituições, que estruturam o comportamento no jogo político, são uma forma das pessoas buscarem reduzir a incerteza e levar adiante seus interesses pessoais. O ponto importante é que as instituições coletivas têm boas e más consequências para o bem-estar individual e comum.

A literatura da TEP é bastante cética quanto à possibilidade da escolha coletiva ser eficiente. Segundo essa linha de estudos, os processos políticos ocorrem dentro de um quadro institucional estabelecido, repleto de incentivos perversos, com informações caras e tendenciosas, tornando a escolha coletiva economicamente ineficiente. As políticas democráticas, em consequência, não são realmente o governo do povo, mas, em vez disso, são uma competição intensa por poder mediante votos entre políticos competindo entre $\mathrm{si}^{67}$.

Dessa forma, "nessa competição, os políticos acham altamente racional provocar confusões, atuar, inventar mitos, fazer rituais, esconder e distorcer informações, estimular o ódio e a inveja. Os eleitores, em contrapartida, acham altamente racional serem racionalmente ignorantes, serem governados por ideologias e se absterem da participação política individual. Portanto, na escolha coletiva, todos são exonerados de responsabilidade" ${ }^{38}$.

\section{Considerações finais}

No campo da Economia, há duas abordagens principais sobre a atuação do Estado na regulação econômica. De um lado a teoria chamada de "análise normativa como uma teoria positiva" que se baseia no que deve ser a regulação econômica.

\footnotetext{
${ }^{66}$ ROSE-ACKERMAN, Susan. Análise econômica progressista do direito - e o novo direito administrativo. In: MATTOS, Paulo et al. (Coord.). Regulação econômica e democracia: o debate norte-americano. São Paulo: Ed. 34, 2004. p. 243-280.

${ }^{67}$ MITCHELL, William C.; SIMMONS, Randy T. Para além da política: mercados, bemestar social e o fracasso da burocracia. Rio de Janeiro: Topbooks, 2003. p. 144.

${ }^{68}$ Ibidem, p. 144.
} 
De outro, há uma análise positiva, elaborada pela economia política, que destaca a distância entre os objetivos da regulação e a dinâmica própria dos entes regulatórios, que está condicionada às motivações de diversos grupos de interesse.

A análise normativa enfatiza que o mercado apresenta falhas que devem ser corrigidas pelo governo por meio de atividades regulatórias. As principais falhas são imperfeições na concorrência - em geral monopólios ou oligopólios -, externalidades, assimetrias de informação e insuficiente provisão de bens públicos.

A análise positiva - denominada Teoria da Regulação Econômica - incorpora elementos da ciência política para avaliar as limitações da aplicabilidade das soluções normativas. Nesse sentido, a teoria analisa as falhas de governo que dificultam a implementação de políticas que deveriam ser estabelecidas - sob o ângulo normativo - para solucionar falhas de mercado.

A Teoria da Escolha Pública aplica o instrumental da Economia no estudo do processo de decisão política numa democracia. Eleitores, políticos, burocratas e grupos de interesse são idealizados como maximizadores de interesses próprios e agentes racionais. A TEP é cética quanto à eficiência de uma escolha coletiva - escolha pública. A democracia seria incapaz de responder às demandas individuais. A abordagem aponta no sentido de reduzir o tamanho do Estado, pois a representação democrática não consegue responder aos anseios dos indivíduos e distorce o funcionamento do mercado que seria a forma mais eficiente de alocação de recursos.

Segundo Salgado, as teorias da Escolha Pública e da Regulação Econômica entendem que o interesse público já é representado de forma eficiente por meio do mecanismo do mercado; qualquer outra instituição, como o mercado político, apenas contribui para confundir os sinais fornecidos pelo sistema de preços e compromete a eficiência do sistema. O pressuposto é de que o livre mercado é a representação perfeita do interesse público ${ }^{69}$.

Porém, importante ressalvar que a TEP é bem mais cética do que a Teoria da Regulação Econômica quanto à possibilidade do governo promover bem-

${ }^{69}$ SALGADO, Lucia Helena. Agências regulatórias na experiência brasileira: um panorama do atual desenho institucional. Brasília: IPEA. 2003. p. 9. (Texto para discussão, n. 941). 
estar social. Esta última teoria busca uma saída para a atuação governamental, incorporando as variáveis políticas, por meio do conceito de remediableness, que assevera que uma política para a qual não existe nenhuma alternativa superior viável que possa ser implementada com ganhos líquidos é presumida como sendo eficiente.

Estas teorias da regulação tentam descrever o comportamento dos agentes que regulam a atividade econômica, sendo uma reação à Teoria do Interesse Público. As falhas dos reguladores em servir ao interesse público são utilizadas como críticas aos fundamentos da intervenção estatal para a correção das falhas de mercado. É argumentado que os reguladores não buscam a maximização do bem-estar, assim não seria nenhum acidente que as decisões dos reguladores resultem em ineficiência econômica e perdas para o bem-estar social ${ }^{70}$.

Os ensinamentos dessas teorias são fundamentais para o processo de elaboração de regras e procedimentos - atividade em que o Direito é peça-chave - para a viabilização de políticas públicas regulatórias que possam superar as falhas de mercado e de governo, promover o bem-estar e a eficiência econômica.

\section{Market failures and government failures: an assessment of the economic regulation literature}

\section{Abstract}

Brief assessment of the economic regulation literature, under an economic perspective, dealing with the two competitive approaches in this area. By one side, the normative analysis of the positive theory of regulation, which deals with the ways under which economic regulation ought to be done. On the other side, the economic theory of regulation which is concerned with the understanding on how regulation is actually done, including the political variables.

Keywords: Economic regulation. Theory of economic regulation. Market failures. Government failures. Public choice theory.

\footnotetext{
${ }^{70}$ SPULBER, Daniel F. Regulation and markets. Massachuesetts: MIT, 1989. p. 98.
} 


\section{Referências}

ANDRADE, Eduardo de Carvalho. Externalidades. In: ARVATE, Paulo Roberto; BIDERMAN, Ciro (Org). Economia do setor público. Rio de Janeiro: Elsevier, 2004. p. 16-33.

ARAGÃO, Alexandre Santos de. Agências reguladoras e a evolução do direito administrativo econômico. Rio de Janeiro: Forense, 2004.

ARROW, K. J. Aspects of the theory of risk bearing. Helsinki: Yrjo Johnassonin Säatio, 1965.

ARROW, K. J. Uncertainty and welfare economics of medical care. American Economic Review, n. 53, p. 941-973, Dec. 1963.

BARRIONUEVO FILHO, Arthur; LUCINDA, Cláudio Ribeiro. Teoria da regulação. In: ARVATE, Paulo Roberto; BIDERMAN, Ciro (Org.). Economia do setor público. Rio de Janeiro: Elsevier, 2004. p. 47-71.

BECKER, Gary S. A theory of competition among pressure groups for political influence. Quarterly Journal of Economics, n. 98, p. 371-400, 1983

BORSANI. Relações entre política e economia: teoria da escolha pública In: ARVATE, Paulo Roberto; BIDERMAN, Ciro (Org.). Economia do setor público. Rio de Janeiro: Elsevier, 2004. p. 103-126.

DI PIETRO, Maria Sylvia Zanello. Limites da função reguladora das agências diante do princípio da legalidade. In: DI PIETRO, Maria Sylvia Zanello (Coord.). Direito regulatório: temas polêmicos. 2. ed. Belo Horizonte: Fórum, 2004. p. 19-50.

FERREIRA, Sandro de Freitas; ORTIZ, Ramon Arigoni. O papel do governo na preservação do meio ambiente. In: ARVATE, Paulo Roberto; BIDERMAN, Ciro (Org.). Economia do setor público. Rio de Janeiro: Elsevier, 2004. p. 34- 46.

FIANI, Ronaldo. Teoria da regulação econômica: estado atual e perspectivas futuras. Rio de Janeiro. UFRJ; IE, 1998. p. 23. (Texto para discussão). Disponível em: <http://www.ie.ufrj.br/grc/pdfs/teoria_da_ regulacao_ economica.pdf $>$. Acesso em: 30 jul. 2008.

FIANI, Ronaldo; PINTO JR., Helder Queiroz. Regulação econômica. In: KUPFER, David; HASENCLEVER, Lia. Economia industrial: fundamentos teóricos e práticos no Brasil. Rio de Janeiro: Campus, 2002. p. 515-545. 
JUSTEN FILHO, Marçal. O direito das agências reguladoras independentes. São Paulo: Dialética, 2002.

MARQUES NETO, Floriano de Azevedo. Agências reguladoras independentes: fundamentos e seu regime jurídico. Belo Horizonte: Fórum, 2005.

MATTOS, Paulo et al. (Coord.). Regulação econômica e democracia: o debate norte-americano. São Paulo: Ed. 34, 2004.

MITCHELL, William C.; SIMMONS, Randy T. Para além da política: mercados, bem-estar social e o fracasso da burocracia. Rio de Janeiro: Topbooks, 2003.

MUELLER, Bernardo. Regulação, informação e política: uma resenha da teoria política positiva da regulação. Revista Brasileira de Economia de Empresas, Vol.1, No 1, p. 9-29.

NISKANEN, W. Bureaucracy and representative government. Chicago; New York: Aldine Atherton, 1971.

OLSON, Mancur. A lógica da ação coletiva: os benefícios públicos e uma teoria dos grupos sociais. São Paulo: EDUSP, 1999.

PELTZMAN, S. A teoria econômica da regulação depois de uma década de desregulação. In: MATTOS, Paulo et al. (Coord.). Regulação econômica e democracia: o debate norte-americano. São Paulo: Ed. 34, 2004. p. 81-127.

PELTZMAN, S. The economic theory of regulation after a decade of deregulation. In: WINSTON, Clifford; BAILY Martin Neil (Ed.). Brookings papers on economic activity: microeconomics. Washington: Brookings Institution Press, 1989.

. Towards a more general theory of regulation. Journal of Law and Economics, v. 19, n. 2, p. 211-240, Aug. 1976.

PINDYCK, Robert S.; RUBINFELD Daniel L. Microeconomia. 5. ed. São Paulo: Prentice Hall, 2002.

POSNER, Richard A. Theories of economic regulation. [S.l.]: NBER, 1974. (Working paper, n. 41).

ROSE-ACKERMAN, Susan. Análise econômica progressista do direito - e o novo direito administrativo. In: MATTOS, Paulo et al. (Coord.). Regulação econômica e democracia: o debate norte-americano. São Paulo: Ed. 34, 2004. p. 243-280. 
SALGADO, Lucia Helena. Agências regulatórias na experiência brasileira: um panorama do atual desenho institucional. Brasília: IPEA. 2003. (Texto para discussão, n. 941).

SAMUELSON, Paul A. The pure theory of public expenditure. The Review of Economics and Statistics, v. 36, n. 4, p. 387-389, nov. 1954.

SPULBER, Daniel F. Regulation and markets. Massachusetts: MIT, 1989.

STIGLER, George J. Teoria da regulação econômica. In: MATTOS, Paulo et al. (Coord.). Regulação econômica e democracia: o debate norte-americano. São Paulo: Ed. 34, 2004. p. 23-48.

. The theory of economic regulation. The Bell Journal of Economics and Management Science, v. 2, n. 1, p. 1-21, Spring 1971.

VARIAN, H. R. Microeconomia: princípios básicos. Rio de Janeiro: Campus, 1994.

WILLIAMSON, O. E. The Politics and Economics of Redistribution and Efficiency. In: THE MECHANISMS of governance. Oxford: Oxford University Press, 1996. 
